\title{
0 abatimento mecanizado de rochas instáveis e segurança no trabalho em mina subterrânea de ouro
}

\section{The mechanical scaling of unstable rocks and work safety in an underground gold mine \\ El abatimiento mecanizado de rocas inestables y la seguridad en el trabajo en una mina subterránea de oro}

Recebido: 10/10/2017

Aprovado: 01/05/2018

Publicado: 27/09/2018

\section{Mario Parreiras de Faria ${ }^{1}$ Ada Ávila Assunção²}

Nos últimos anos, a introdução de um equipamento chamado de scaler buscou controlar a exposição ao risco de acidentes durante a atividade de abatimento de "choco". Os objetivos deste artigo são analisar as vantagens e limitações da tecnologia de abatimento mecanizado de rochas instáveis; identificar as dificuldades e os riscos para os operadores e as estratégias utilizadas no desempenho da atividade. Realizou-se pesquisa qualitativa, combinando análise documental e entrevistas com seis trabalhadores durante quatro sessões coletivas, utilizando roteiro prévio. 0 uso do scaler trouxe benefícios para a segurança e minimizou o esforço físico necessário na atividade. Fatores organizacionais e a concepção do equipamento agravam a situação, uma vez que não levam em conta as características físicas e psicológicas dos operadores e a gestão implicada na atividade.

Descritores: Mineração; Saúde do trabalhador; Prevenção de acidentes.

In recent years, a device called scaler was introduced, aimed to control exposure to the risk of accidents during the activity of elimination of "choco". The objectives of this article are to analyze the advantages and limitations of the mechanized technology for elimination of unstable rocks; to identify the difficulties and the risks for the operators and the strategies used in the execution of this activity. A qualitative approach was used, combining documental analysis and interviews with six workers during four collective sessions, using a script as a guide. The use of the scaler has brought benefits to the safety and has also minimized the physical effort required by the activity. Organizational factors and the design of the equipment worsen the situation, since the latter does not take into account the physical and psychological characteristics of the operators, neither does the management involved in the activity.

Descriptors: Mining; Occupational health; Accident prevention.

En los últimos años, la introducción de un equipamiento llamado scaler buscó controlar la exposición al riesgo de accidentes durante la actividad de abatimiento de "choco". Los objetivos de este artículo son analizar las ventajas y limitaciones de la tecnología de abatimiento mecanizado de rocas inestables; identificar las dificultades y los riesgos para los operadores y las estrategias utilizadas en el desempeño de la actividad. Se realizó una investigación cualitativa, combinando análisis documental y entrevistas con seis trabajadores durante cuatro sesiones colectivas, utilizando guión previo. El uso del scaler trajo beneficios para la seguridad y minimizó el esfuerzo físico necesario en la actividad. Factores organizacionales y la concepción del equipamiento agravan la situación, dado que no tienen en cuenta las características físicas y psicológicas de los operadores y la gestión implicada en la actividad.

Descriptores: Minería; Salud laboral; Prevención de acidentes.

1. Médico. Especialista em Medicina do Trabalho. Mestre em Saúde Pública. Auditor Fiscal do Trabalho do Ministério do Trabalho, Brasília, Brasil. ORCID: 0000-0002-3496-8664 E-mail: marioparreiras55@gmail.com

2. Médica. Especialista em Medicina Preventiva. Especialista em Medicina do Trabalho. Mestre e Doutora em Ergonomia. PósDoutorado em Saúde Pública. Professora Associada do Departamento de Medicina Preventiva e Social da Universidade Federal de Minas Gerais, Belo Horizonte MG, Brasil. ORCID:0000-0003-2123-0422 E-mail: adavila@medicina.ufmg.br 


\section{INTRODUÇÃO}

$\mathbf{0}$ setor extrativo elevadas taxas relacionada aos

mineral registra de mortalidade acidentes de trabalho ${ }^{1-4}$. Tais acidentes são causados por diversos fatores, como explosão de gases ou poeira, problemas relacionados à eletricidade, quedas de rochas dos tetos e paredes de galerias de minas subterrâneas ${ }^{5}$. Quanto aos últimos, de um lado, provocam lesões, incapacidade, morte e sofrimento; e, de outro lado, quebras de equipamentos, interrupção das operações e altos custos decorrentes dos prejuízos produtivos e sociais ${ }^{6,7}$.

Em minas de ouro, a prevalência de mortalidade relacionada às quedas de rochas é três vezes maior quando comparada à média do setor em geral ${ }^{8}$. Em 1995, ocorreram 2.068 incidentes desse tipo em minas de ouro e platina na África do Sul, os quais resultaram em 198 mortes. As quedas de rochas ocuparam o primeiro lugar entre as causas de morte nas minerações sulafricanas, no período de 1996 a 2005. No ano de 1999, 62,6\% do total de acidentes fatais $(n=107)$ na indústria da mineração de ouro foram ocasionados por quedas de rochas ${ }^{9}$.

Nos Estados Unidos da América do Norte (EUA), em 1999, a taxa de mortalidade foi 20 vezes maior em minerações subterrâneas quando comparadas aos setores industriais. Quase 75\% das mortes são devidas aos impactos das quedas de rochas dos tetos ou laterais das galerias sobre o trabalhador. Entre 1996 e 1998, ocorreram 256 acidentes fatais no setor da mineração daquele país, dos quais 45 foram causados por quedas de rochas ${ }^{10}$.

Para diminuir a insegurança nas minas, os operadores identificam rochas instáveis "chocos", para o senso-comum - antes de iniciar a jornada propriamente dita. Uma vez identificados, nos tetos e laterais das galerias em minas subterrâneas, os "chocos" devem ser retirados (abatidos), utilizando, na maioria das minas, uma alavanca metálica. 0 nome "choco" vem do fato de que a percussão das rochas instáveis com a alavanca metálica produz um som "choco", revelando que aquela porção de rocha está descolada do maciço rochoso e, portanto, com risco de cair sobre os trabalhadores ou máquinas e equipamentos da mina ${ }^{11}$.

Esses operadores que identificam e abatem "chocos" trabalham em situação de risco. Em minerações subterrâneas de calcário, nos EUA, entre 1984 a 1994, cerca de um terço do total de 201 acidentes registrados nas atividades de controle de maciços rochosos estava relacionado às atividades de abatimento de "choco". Esses acidentes resultaram em 11 mortes, entre elas, a de um operador trabalhando no abatimento de rochas com o equipamento scaler $^{11 .}$.

O scaler é um equipamento de grande porte que se desloca sobre pneus, sendo dotado de um braço mecânico telescópico que pode se estender por até nove metros, que é utilizado no abatimento de rochas permitindo a seu operador permanecer distante do local do "choco" a ser abatido.

Nos últimos anos, a introdução do scaler é uma inovação que visou controlar a exposição ao risco de acidentes durante a atividade de abatimento de "choco". A implantação da nova tecnologia permite, em minas dotadas de galerias mais amplas, aumentar a produtividade e conferir maior segurança, pois o operador fica protegido no interior da cabine $^{12}$, conforme ilustra a Figura 1.

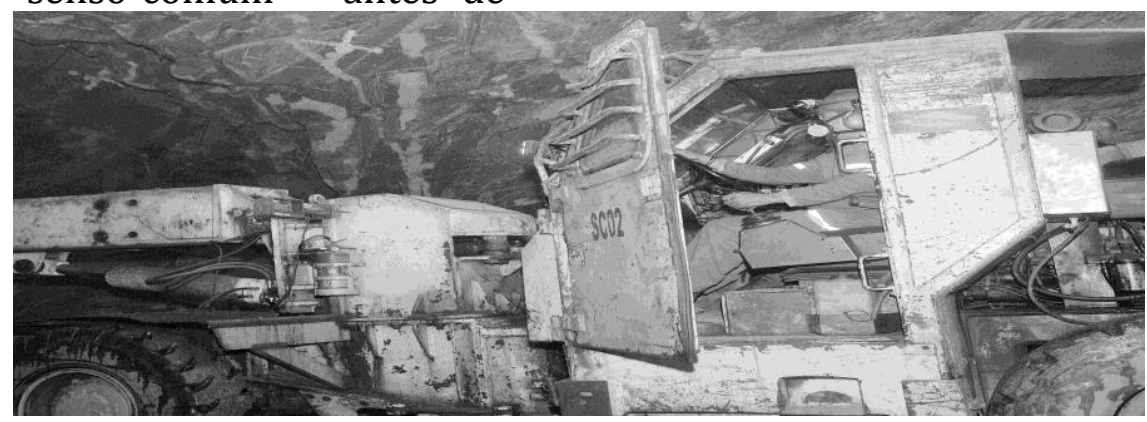

Figura 1. Foto ilustrativa da cabina e do operador de scaler. 
Este estudo tem como objetivos: analisar as vantagens e limitações da tecnologia de abatimento mecanizado de rochas instáveis e, identificar as dificuldades e os riscos para os operadores de equipamento mecanizado e as estratégias utilizadas no desempenho de sua atividade.

\section{MÉTODO}

Realizou-se uma pesquisa durante os anos de 2006 e 2007 utilizando uma abordagem qualitativa, combinando análise documental e entrevistas com grupos de trabalhadores envolvidos na tarefa de abatimento de "chocos" em uma mina subterrânea de ouro com 800 metros de profundidade, 840 empregados e localizada em Minas Gerais, Brasil,

Os critérios para a seleção dos sujeitos foram: estar em exercício da atividade de abatimento de "chocos" no momento da pesquisa e aceitar participar da pesquisa foco do estudo.

Foram realizadas entrevistas de acordo com o roteiro prévio que, em vez de perguntas, orientou-se por temas de interesse, sendo eles: a) a descrição do trabalho; b) a ocorrência de imprevistos durante a tarefa; c) o encontro e a identificação de rochas instáveis; d) os acidentes vivenciados; e) o trabalho com scaler e o abatimento manual. A depender do conteúdo dos discursos colhidos, os entrevistadores formularam novas questões em tempo real.

As entrevistas foram efetivadas em quatro sessões (uma por semana), num período de 29 dias, durante o ano de 2007. As entrevistas foram gravadas após a assinatura pelos entrevistados do termo de consentimento livre e esclarecido, garantindo-se o anonimato. A duração total das entrevistas foi de 308 minutos, tendo duração, cada uma, entre 60 e 97 minutos.

Visando a estimular a discussão com o grupo de operadores, utilizou-se a técnica do incidente crítico $^{13}$. Foi solicitada aos participantes a descrição de incidentes associados aos resultados insatisfatórios ou aos acidentes. Os trabalhadores foram estimulados a explicitar eventos positivos ou bem-sucedidos, para evitar o foco exclusivo nos problemas ou nas situações críticas esperadas em situações de inovações tecnológicas, pois um tema como a mudança tecnológica não deve necessariamente ser reduzido a aspectos problemáticos ${ }^{14}$.

Procedeu-se análise qualitativa do conteúdo das entrevistas, construindo-se um quadro de categorias analíticas ${ }^{15}$. Essa análise permitiu descrever as propriedades específicas aos métodos de segurança e o conjunto de relações que envolviam o trabalho com o scaler.

A análise do material se deu num processo de vai-e-vem. Assim, o estudo das entrevistas passou por um processo em espiral, por meio do qual o material foi trabalhado em múltiplas etapas que se sucediam uma às outras. Os cuidados éticos deste estudo foram tomados com aprovação do projeto no Comitê de Ética em Pesquisa da Universidade Federal de Minas Gerais (Parecer ETIC 31/07).

\section{RESULTADOS}

A amostra de seis trabalhadores integra o universo de quarenta e um trabalhadores envolvidos na tarefa de abatimento manual ou mecanizado de "chocos". A Tabela 1 apresenta as características dos operadores selecionados.

Tabela 1. Trabalhadores na mina subterrânea de ouro de acordo idade, tempo de serviço e função. Minas Gerais, 2007.

\begin{tabular}{lll}
\hline Idade & Tempo na empresa & Função atual \\
\hline OP1 - 39 anos & 7 anos & Operador de scaler \\
OP2 - 39 anos & 15 anos e 6 meses & Operador de scaler \\
OP3 - 39 anos & 6 anos e 9 meses & Operador de scaler \\
OP4 - 30 anos & 1 ano e 2 meses & Auxiliar de scaler \\
OP5 - 34 anos & 1 ano e 6 meses & Abatimento manual \\
OP6 - 24 anos & 11 meses & Auxiliar de abatimento manual \\
\hline
\end{tabular}


Como categorias apresentadas tem-se: Fatores Intrínsecos; $A$ introdução $d a$ tecnologia e os limites do scaler; Fatores Extrínsecos: a introdução do scaler; Fatores Extrínsecos: as normas operacionais e os fatores de risco; e, Fatores Extrínsecos: a manutenção do scaler.

\section{Fatores Intrínsecos}

Para os operadores, o processo de abatimento mecanizado de "chocos" com scaler, se comparado ao processo de abatimento manual, é mais seguro contra os riscos de queda de fragmentos de rochas: "em vista [de] bater 'choco' manual, é muito melhor... Porque manual o risco é maior, gente... comigo mesmo já caiu pedra na cabine... que se não tivesse a cabine eu não tava aqui... [a cabine] protege" (OP. 2).

Adicionalmente, o scaler exigiria menos esforço físico, pois, no caso do abatimento manual, os operadores manuseiam longas e pesadas hastes metálicas para alcançar pontos distantes e mais elevados das galerias:

É risco [de queda de rochas] e o esforço físico (OP 3).

Geralmente, o saneamento manual é muito cansativo, sim" (OP.5,).

\section{A introdução da tecnologia e os limites do scaler}

Sinais sonoros específicos (uma espécie de estalo) indicam a instabilidade do maciço e de seus efeitos como fraturas ou quedas. Além da percepção auditiva, o trabalho solicita percepção visual para identificar a existência de "chocos" após a estabilização do maciço e depende de uma iluminação adequada para identificar as rochas a serem retiradas.

As fontes de iluminação são os faróis instalados no scaler e a lanterna do operador auxiliar. Os auxiliares mantêm a área molhada para diminuir a poeira e sinalizam a presença de "chocos" por meio de lanterna especial ligada ao scaler. Os operadores reconhecem o papel do auxiliar na execução de sua tarefa:

Mesmo tendo esses faróis, ele [o scaler] costuma ter uns pontos cegos...(OP3)

Eu não tenho completamente uma visão periférica. Porque quem tem uma visão periférica é o auxiliar, porque há coisas que eu vejo que ele não vê, entendeu? E vice-versa" (OP1).
A robustez e o porte do equipamento têm como contrapartida a lentidão de seus movimentos, com redução da eficácia da operação de abatimento de rochas e atraso no cumprimento das metas de produção, como observado nas falas de um operador:

O scaler é uma máquina boa... mais é um equipamento lento...é um equipamento robusto e há determinados pontos em que prejudica muito o saneamento perfeito, né? (OP3).

A depender do fabricante do equipamento (Dux $\AA$ ou Gatman $\AA$ ), novas situações são colocadas para o operador. Exemplificando, um dos modelos de scaler gera maior aquecimento da cabine, como apontado por um pesquisado:

Quando você pega o Gatman você trabalha com a porta aberta... esquenta muito. OP1.

Por ser mais leve, o scaler Gatman ${ }^{\circledR}$ não garante a estabilidade da cabine nos casos de abatimento de rochas mais volumosas e pesadas e ocasiona impactos sobre o corpo do operador:

Você toma muito arranco nas costas...o impacto que você recebe na hora que a pedra desce...é como se a gente trombasse um carro... (OP1).

\section{Fatores Extrínsecos: a introdução do scaler}

Apesar da proteção contra os riscos de quedas de rochas, o trabalho na mina com scaler não elimina os danos sobre o corpo e o mal-estar presentes no cotidiano dos operadores, como apontam:

o desconforto também vem depois quando a gente desce dele...as pernas estão queimando (ênfase) demais... e dor de cabeça... (OP3).

\section{Fatores Extrínsecos: as normas operacionais e os fatores de risco}

A distância proposta restringe o campo visual do operador e pode diminuir a capacidade para identificar as rochas instáveis, especialmente aquelas de pequenas dimensões. Um dos operadores, citando umas das áreas em lavra, relata que:

ali não tem como você se posicionar a 20 metros. Você tem que parar, olhar mais ou menos como é que vai ser, muitas vezes você tem que posicionar o scaler indo até o monte e voltando depois. Você tem que fazer essa manobra, entendeu? (OP1).

A cada dia de trabalho, os operadores são designados para trabalhar em locais diferentes, necessitando conhecer as condições do maciço nas diversas frentes. Os 
operadores adotam procedimentos diferenciados e redobram o nível de atenção quando iniciam o trabalho em uma área desconhecida. Se referindo a um determinado tipo de maciço rochoso, um operador enfatiza:

...ali porque eu tenho que ficar mais cabreiro... porque o quartzo estala muito... não segura nada. (OP3).

Visando maior conhecimento sobre o processo e as transformações do maciço, os operadores buscam informações junto a outros técnicos para planejar e executar a tarefa com segurança. Os trabalhadores avaliam suas ações e resultados alcançados posteriormente aos eventos. Para o operador 1:

manda muito a pessoa ter muita experiência e boa vontade de aprender as coisas, né? $E$ adquirir experiência. Cada dia a gente tá aprendendo as coisas. Eu não digo que eu sei tudo não, tô aprendendo ainda, entendeu?

\section{Fatores Extrínsecos: a manutenção do scaler}

As condições ambientais estão associadas ao desgaste dos trabalhadores, mas também dos equipamentos:

No final da conta acaba com a máquina (OP1).

E com o operador; e a uma maior freqüência de panes $e$ de paradas para correções (OP4).

Para os operadores, o scaler:

Quando chega novo, ele chega uma maravilha, quando chega, chega novo...o problema nosso aí, às vezes eles não quiseram falar, é manutenção... a manutenção não é adequada (OP2).

Reforçando a importância da manutenção adequada dos scalers para a execução de uma operação eficaz e para a produção:

Quando tem uma manutenção adequada ele não fica lento, fica mais forte (OP2).

\section{DISCUSSÃo}

A tarefa de abatimento de rochas instáveis com o uso de equipamentos mecanizados reduz os esforços físicos e as condições de risco de acidentes com queda de rochas. No entanto, os acidentes não foram eliminados em virtude de uma série de fatores ligados às condições organizacionais e ambientais e às variabilidades do maciço rochoso.

Em pesquisa no arquivo do Ministério do Trabalho e Emprego, para dados de Minas Gerais, identificou-se que, em apenas uma empresa de mineração subterrânea de ouro, no período de 2000 a 2004, foram registrados 285 acidentes (média anual de 57 acidentes). Desses acidentes, três resultaram em morte. Atribuiu-se 64 acidentes à queda de "chocos" $(22,4 \%)$, e entre estes, dois resultaram em óbitos ${ }^{11}$.

Entre 2007 e 2009, a incidência de acidentes de trabalho no setor mineral brasileiro foi em média 53\% mais elevada do que nos outros setores econômicos 16,17.

Nos anos de 2000 a 2012, dados apresentados em 101 relatórios de acidentes no setor mineral elaborados pela Superintendência Regional do Trabalho de Minas Gerais informam que 79,2\% foram casos fatais. Quanto ao tipo, os impactos provocados por quedas das estruturas rochosas ocuparam o segundo lugar entre as causas dos acidentes $\quad(17,8 \%$ dos acidentes) ${ }^{18}$.

A despeito da subnotificação dos acidentes de trabalho no Brasil ${ }^{19}$, a mineração, no período de 1999 a 2009, registra taxas de mortalidade (número de óbitos/número de empregos no setor econômico X 100.000) de 58,70 a 28,96, enquanto as taxas internacionais variaram de 20,03 a $7,58^{17}$.

No que se refere aos fatores intrínsecos e extrínsecos a Figura 2 ilustra um modelo síntese dos fatores intrínsecos e extrínsecos implicados na atividade de abatimento mecanizado sendo, portanto, uma linha interpretativa dos resultados encontrados. 


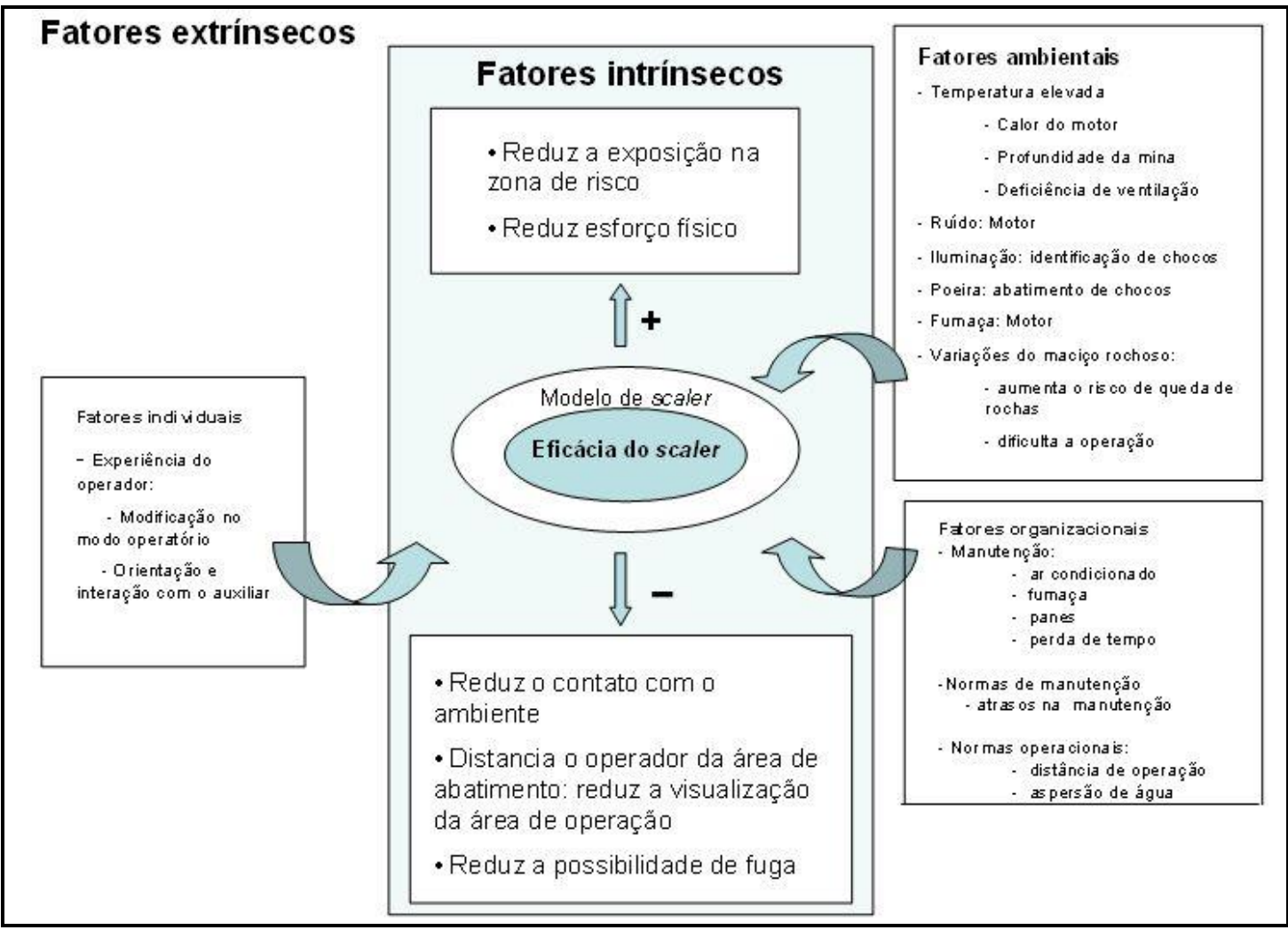

Figura 2: Esquema ilustrativo dos fatores intrínsecos e extrínsecos associados à eficácia do scaler na prevenção de acidentes em mina subterrânea.

Por ser dotado de um braço mecânico movimentado por sistema hidráulico em substituição às hastes, o scaler permite ao operador permanecer afastado da área onde se está realizando o abatimento do "choco".

No entanto, os benefícios do scaler dependem do tipo de áreas trabalhadas. Os operadores mencionam a queda de grandes blocos de rocha sobre os equipamentos, que não resistem aos graves impactos sobre as suas partes ou componentes.

A baixa luminosidade é agravada pelo design da cabine, na qual o campo de visão fica limitado. Os operadores e seus auxiliares são guiados por sinais luminosos ou sonoros, e quando disponíveis, por radiotransmissores, para compartilhar as operações visando, por exemplo, uma melhor posição para o braço mecânico do equipamento. Os tipos de sinais básicos são padronizados, conhecidos e respeitados por todos.

Os operadores enfatizam, mais uma vez, a importância do auxiliar, especialmente na identificação e sinalização da existência de riscos e a necessidade de abandonar o local em caso de emergência.
Os operadores prestam atenção na direção do fluxo luminoso. Sinais ambíguos geram impasses nas decisões, uma vez que pode acontecer também de o operador não ver o sinal luminoso enviado por um colega.

Para melhorar a iluminação e umidificar as frentes de trabalho, os auxiliares se deslocam nas proximidades do scaler. Com isso, causam movimentações aleatórias do facho de luz de sua lanterna não relacionadas a um sinal específico. Diante dessa realidade, é necessária atenção redobrada durante as operações.

0 pequeno espaço no interior da cabine pode dificultar as situações de fuga, como no caso de risco iminente de colapso ou queda descontrolada do maciço rochoso. Esta restrição é agravada pelo uso dos equipamentos de segurança.

Em suma, a implantação do abatimento mecanizado é uma medida de segurança que gera zonas de insegurança, pois a dimensão da cabine do equipamento e sua "lentidão", aliadas ao posicionamento de seus dispositivos de controle (pedais, volante, alavancas e outros.) podem criar dificuldades em situações de fuga. 
O scaler com sistema de percussão em substituição à alavanca é mais confortável, no entanto, ao percutir sobre a rocha produz instabilidade e gera mais "chocos". Por essa razão, foi abandonado.

Durante sua atividade, os operadores de scaler estão expostos à poeira, às temperaturas elevadas, ao ruído e aos gases provenientes do escapamento do motor, e enfrentam as panes do equipamento, o desgaste de peças e a deficiência da manutenção.

A aspersão de água sobre as rochas não é suficiente para eliminar a geração de poeira decorrente da atividade de abatimento de "choco" nem a exposição dos trabalhadores a esse fator de risco.

Para explicar o desconforto na mina, soma-se à poeira a exposição a temperaturas elevadas em áreas mais profundas com restrição de ventilação. 0 funcionamento do motor e da bomba do sistema hidráulico do scaler agrava a nocividade do ambiente.

Outro fator que contribui para o desconforto térmico é o funcionamento inadequado do sistema de ar condicionado da cabine do scaler. Nessa situação, as medidas para aliviar os efeitos do microclima são extremas: tirar o uniforme ou abrir a porta do equipamento na tentativa de minimizar o mal-estar e a sudorese intensa.

A exposição ao ruído proveniente do funcionamento do motor do scaler, à semelhança da exposição a temperaturas elevadas, é motivo de sentimentos negativos.

A empresa estabelece normas de execução que deverão ser cumpridas pelos trabalhadores durante $\mathrm{o}$ abatimento de "chocos", entre as quais a já mencionada aspersão de água sobre o maciço rochoso e sobre o minério desmontado. Os operadores relatam que a aspersão de água durante o abatimento de "choco" interfere na percepção visual das irregularidades ou fissuras nas rochas, as quais são indícios, para os mais experientes, de instabilidades do maciço e do risco de quedas de blocos rochosos.

A aspersão de água, ao provocar um choque térmico no maciço rochoso, aumenta a frequência de "estalos" e perturba a percepção, porque você molha o teto, o minério estala, aí você não sabe se aquele estalo é uma acomodação de rocha ou se é um "choco" grande que vai cair.

Entre os fatores que conferem complexidade à tarefa de abatimento de "choco" tem-se, ainda, as variações do comportamento do maciço rochoso da mina em lavra que, além de sofrer influências das detonações, apresenta alterações na sua estrutura em função dos tipos de rocha que compõem os diversos corpos minerais.

0 desgaste do equipamento $\mathrm{e}$ as dificuldades de manutenção ocasionam problemas como vazamentos em seu sistema hidráulico e levam à redução da potência da alavanca do equipamento e consequente perda da eficácia no abatimento de "choco".

As normas da empresa exigem a autorização da hierarquia para interromper o trabalho e deslocar o equipamento até a oficina localizada na superfície da mina nos casos de defeitos ou avarias mais sérias. Os operadores criticam essas normas devido aos atrasos decorrentes da ausência de autonomia para resolver um problema.

Face às dificuldades de se obter a presença dos mecânicos de manutenção e na tentativa de contornar as dificuldades advindas de defeitos do equipamento, os operadores tomam a iniciativa de realizar reparos nos próprios locais de trabalho no subsolo. Ademais, as iniciativas dos operadores em reparar alguma pane esbarram nas normas da produção e não são reconhecidas pela hierarquia, gerando conflitos entre operadores e gerentes.

Face aos imprevistos, às dificuldades e aos perigos que surgem durante sua atividade, os trabalhadores da mina expressam sentimentos ambíguos de admissão e negação do medo. Em situação de risco, os trabalhadores conseguem reconhecer o perigo e distinguir situações que, apesar das aparências, não são perigosas $^{19}$.

Os mecanismos que buscam aumentar o nível de segurança podem produzir novos riscos e novos tipos de acidentes. Houve redução da ocorrência de acidentes relacionados às explosões do gás metano 
após introdução da lâmpada de Davy nas minas inglesas de carvão, mas lembra o concomitante aumento do número de acidentes por desabamentos de rochas nas áreas mais profundas ${ }^{20}$.

A utilização do scaler só é possível em ambientes de galerias mais amplas e de grandes corpos minerais, tornando viável $o$ desmonte de maiores volumes de rocha por meio de grandes quantidades de explosivos. Essas são situações conhecidas de insegurança do trabalho devido ao deslocamento e queda de blocos rochosos.

Os operadores entrevistados referem a lentidão e as dificuldades de movimentação do equipamento durante o abatimento de "choco". O scaler apresenta bom nível de segurança para a operação, mas, em função de seu tamanho e peso, a mudança de direção e posicionamento é pesada e implica esforços adicionais.

Os operadores são conscientes das limitações na interação com o ambiente, a qual é considerada fundamental para a gestão individual do risco. As características da cabine do scaler reduzem a segurança ecológica e ocasionam perturbações na identificação de rochas instáveis. O campo visual dos operadores é restrito quando se trabalha no interior da cabine. São situações semelhantes de um estudo sobre acidentes relacionados à queda de árvores ${ }^{21}$.

Quanto aos diferentes tipos de scaler disponíveis no mercado, relata-se que a utilização de um determinado modelo em mineração de ouro levou ao surgimento de novos "chocos" durante a operação de abatimento, explicando a expansão de tarefas manuais no decorrer do processo ${ }^{12}$.

Os dados colhidos das entrevistas indicam que a situação é mantida sob controle por meio de um esforço ativo dos trabalhadores para corrigir os desvios e disfunções, como ilustra o exemplo do procedimento de molhar pontos da frente de trabalho distantes do equipamento em uso.

No compromisso de obter uma solução para a dificuldade apresentada durante a ação, os operadores mantêm a situação sob controle, num processo, que é descrito como gestão dinâmica da atividade ${ }^{22}$. A regulação do tempo da operação para aumentar sua segurança após aspergir água na frente de trabalho é um procedimento diferente daquele padronizado pela hierarquia $e$ constitui uma saída para enfrentar as dificuldades e constrangimentos surgidos durante o trabalho, na busca de eficácia e segurança em sua tarefa.

Molhar a rocha, para diminuir a poeira, dificulta a percepção de indícios de queda. Este paradoxo está na base de elaboração de estratégias operatórias finas pelos operadores junto ao auxiliar, as quais permitem o desenvolvimento de competências e de modos operatórios para facilitar a operação e ampliar a segurança. Quando o operador altera a forma prescrita de aspersão de água sobre a frente de trabalho para reduzir as dificuldades de percepção de indícios de queda de rocha, ele estaria mobilizando o chamado "sexto sentido" ou "senso de mineração" 20 .

Os resultados aqui apresentados são convergentes com outros estudos sobre o papel da organização do trabalho no desenvolvimento de modos operatórios seguros pelos trabalhadores ${ }^{23,24}$. Viu-se que operadores tentam cumprir os objetivos estabelecidos, sustentando-se em redes informais de conhecimentos de outros profissionais ou setores de trabalho.

As redes solidárias em torno das situações de trabalho permitem compartilhar as ações e os seus efeitos, ressaltando o nível de cooperação necessário para sua execução de modo produtivo e seguro ${ }^{23}$.

\section{CONCLUSÃO}

Os operadores de scaler e seus auxiliares estão submetidos a um conjunto de dificuldades determinadas pelos fatores ambientais. As dificuldades podem ser agravadas pelas normas organizacionais.

Os operadores revelaram conhecer os riscos e as ameaças latentes de sua atividade. Maior segurança no trabalho poderia ser alcançada em um ambiente organizacional menos rígido, dando voz aos trabalhadores na busca da solução dos problemas surgidos no trabalho, revalorizando sua intuição e experiência, ao contrário de medidas que 
primam pela imposição de normas de engenharia de segurança ou da legislação.

Os trabalhadores também adaptam suas ações às condições reais de trabalho e às coerções do ambiente e do contexto de trabalho, não explicitados nos procedimentos formais, para atingir os objetivos da produção com segurança. Os resultados das entrevistas indicam que parte considerável da iniciativa fica sob o domínio dos trabalhadores e não da estrutura hierárquica, em que pesem as prescrições gerenciais.

Por fim, a implantação de métodos de prevenção e as intervenções consideradas seguras, quando não incorporam a abordagem das relações dinâmicas no ambiente e das relações sociais existentes, podem explicar a produção de novos tipos de acidentes.

\section{REFERÊNCIAS}

1. Peake AV, Ashworth SGE. Factors influencing the detections of unsafe hanging wall conditions: final project report [Internet]. [Pretória]: CSIR, SIMRAC; Out 1996 [citado em 10 ago 2016]. (GAP 202). Disponível em: http://www.mhsc.org.za/sites/default/files/G AP_2021.pdf

2. Trotter DA, Kopeschny FV. Cap lamp improvement in canadian mines. Appl Occup Environ Hyg. 1997; 12(12):859-63.

3. Gyekye SA. Causal attributions of Ghanaian industrial workers for accident occurrence: miners and non-miners perspective. J Safety Res. 2003; 34(5):533-8.

4. Ghosh AK, Bhattacherje A, Chau N. Relationships of working conditions and individual characteristics to occupational Injuries: a case-control study in coal miners. J Occup Health. 2004; 46(6):470-8.

5. Vingård E, Elgstrand K. Safety and health in mining. In: Elgstrand $\mathrm{K}$, Vingård $\mathrm{E}$, editores. Occupational safety and health in mining: anthology on the situation in 16 mining countries [Internet]. Gothenburg: University of Gothenburg; 2013 [citado em 17 ago 2016]. p. 1-14. (Arbete och Hälsa; vol 47; n 2). Disponível em:

https://gupea.ub.gu.se/bitstream/2077/32882 /1/gupea_2077_32882_1.pdf

6. Hull BP, Leigh J, Driscoll TR, Mandryk J. Factors associated with occupational severity in New South Wales underground coal mining industry. Saf Sci. 1996; 21(3):191-204.

7. Duzgun HSB, Einstein HH. Assessment and management of roof falls risks in underground coal mines. Saf Sci. 2004; 42(1):23-41.

8. Leger J. Trends and causes of fatalities in South African mines. Saf Sci. 1991; 14(3):16985.

9. Jaku EP, Toper AZ, Jager AJ. Updating and maintaining accident database: final project report [Internet]. [Pretória]: CSIR, SIMRAC; Mar. 2001 [citado em 17 ago 2016]. (GAP 727). Disponível

em: http://researchspace.csir.co.za/dspace/bitstre am/10204/1819/1/GAP727.pdf

10. Mark C, Iannacchione AT. Best practices to mitigate injuries and fatalities from rock falls. In: Annual Institute of Mining Health, Safety and Research; 31; 2000; Blacksburg. Proceedings ... Blacksbourg: Virginia Polytechnic Institute and State University; 2000. p.115-130.

11. Grau III RH, Prosser LJ Scaling accidents in underground stone mines. In: Rock Products. p. $39-41$.

12. Ottermann RW, Burger NDL, Wielligh AJ, Handley MF, Fourie GA. Investigate a possible system for 'making safe': final project report. [Internet]. [Pretória]: CSIR, SIMRAC; Feb 2002 [citado em 18 ago 2016]. (GEN 801). Disponível em:

http://www.mhsc.org.za/sites/default/files/G en801_report_final.pdf

13. Vicente KJ. Homens e máquinas: como a tecnologia pode revolucionar a vida cotidiana. Estrada MID, tradutora. Rio de Janeiro: Ediouro; 2005.

14. Bauer MW, Gaskell G. Pesquisa qualitativa com texto, imagem e som: um manual prático. Guareschi PA, tradutor. 2ed. Petrópolis: Vozes; 2002.

15. Maroy C. A análise qualitativa de entrevistas. In: Albarello $\mathrm{L}$, Digneffe $\mathrm{F}$, Hiernaux J-P, Maroy C, Ruquoy D, SaintGeorges P. Práticas e métodos de investigação em ciências sociais. Lisboa: Gradiva; 1997. p. 117-156.

16. Faria MP. Fatores intervenientes na segurança do trabalho de abatimento mecanizado de rochas instáveis em uma mina subterrânea de ouro. [dissertação]. Belo Horizonte, MG: Universidade Federal de Minas Gerais; 2008. 66 p. 
17. Faria MP, Dwyer T. Safety and health in mining in Brazil. In: Elgstrand $\mathrm{K}$, Vingård $\mathrm{E}$, editors. Occupational Safety and Health in Mining: anthology on the situation in 16 mining countries [Internet]. Gothenburg: University of Gothenburg; 2013 [citado em 17 ago 2016]. p. 150-69. (Arbete och Hälsa; vol 47; n 2). Disponível

em:

https://gupea.ub.gu.se/bitstream/2077/32882 /1/gupea_2077_32882_1.pdf

18. Candia RC, Campos VM, Faria MP. Estudo de acidentalidade na mineração no Estado de Minas Gerais. In: $8^{\circ}$ Congresso Brasileiro de Minas a Céu Aberto, $8^{\circ}$ Congresso Brasileiro de Mina Subterrânea, Workshop Economia Mineral: Recursos e Reservas [Internet]; 6-8 ago; 2014, Belo Horizonte, Brasil. Belo Horizonte: IBRAM, UFMG; 2014 [citado em 17 ago 2016]. Disponível em: http://www.ibram.org.br/sites/1300/1382/0 0005702.pdf

19. Correa PRL, Assunção AA. A subnotificação de mortes por acidentes de trabalho: estudo de três bancos de dados. Epidemiol Serv Saúde. 2003; 12(4):203-12.

20. Dwyer, TP. Vida e morte no trabalho: acidentes e a produção social do erro. Brant
WC, Amado J, tradutores. Campinas: Unicamp; Rio de Janeiro: Multiação Editorial; 2006.

21. Schepens F. L'erreur est humaine mais non professionelle: le bücheron et l'accident. Sociologie du Travail. 2005; 47(1):1-16.

22. Amalberti R. Gestão da segurança: teorias e práticas sobre as decisões e soluções de compromisso necessárias. Mussulini D, tradutora. Botucatu: FMB-UNESP ; 2016.

23. Diniz EPH, Assunção AA, Lima FAP. Prevenção de acidentes: o reconhecimento das estratégias operatórias dos motociclistas profissionais com base para negociação de acordo coletivo. Ciênc Saúde Colet. 2005; 10(4):905-16.

24. Fonseca ED, Lima FAP. Novas tecnologias construtivas e acidentes na construção civil: o caso da introdução de um novo sistema de escoramento de formas de laje. Rev Bras Saúde Ocup. 2007; 32(115):63-7.

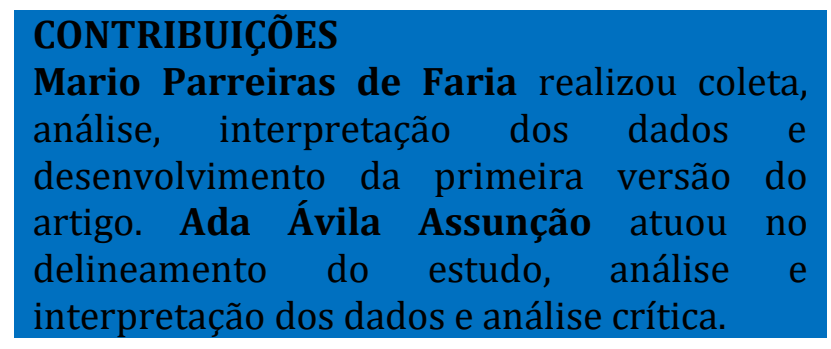

\footnotetext{
Como citar este artigo (Vancouver)

Faria MP, Assunção AA. O abatimento mecanizado de rochas instáveis e segurança no trabalho em mina subterrânea de ouro. REFACS [Internet]. 2018 [citado em inserir dia, mês e ano de acesso]; 6(Supl. 2):542-551. Disponível em: inserir link de acesso. DOI: inserir link do DOI.

\section{Como citar este artigo (ABNT)}

FARIA, M. P. de; ASSUNÇÃO, A. A. O abatimento mecanizado de rochas instáveis e segurança no trabalho em mina subterrânea de ouro. REFACS, Uberaba, MG, v. 6, supl. 2, p. 542-551, 2018. Disponível em: <inserir link de acesso>. Acesso em: inserir dia, mês e ano de acesso. DOI: inserir link do DOI.

Como citar este artigo (APA)

Faria, M. P. de \& Assunção, A. A. (2018). O abatimento mecanizado de rochas instáveis e segurança no trabalho em mina subterrânea de ouro. REFACS, 6(Supl 2), 542-551. Recuperado em: inserir dia, mês e ano de acesso de inserir link de acesso. DOI: inserir link do DOI.
} 